\title{
Pseudolymphomatous Folliculitis on the Nose
}

\author{
Aya Kakizaki Taku Fujimura Ikuko Numata \\ Akira Hashimoto Setsuya Aiba \\ Department of Dermatology, Tohoku University Graduate School of Medicine, \\ Sendai, Japan
}

\section{Key Words}

Pseudolymphomatous folliculitis · Cutaneous lymphoid hyperplasias .

Pseudolymphoma $\cdot \mathrm{CD} 1 \mathrm{a}$

\begin{abstract}
Pseudolymphomatous folliculitis (PLF), which sometimes mimicks cutaneous lymphoma, is a rare manifestation of cutaneous pseudolymphoma and cutaneous lymphoid hyperplasia. We describe a 57-year-old Japanese woman with PLF on the nose that resembled cutaneous lymphoma clinically. The biopsy specimen revealed dense lymphocytes, especially CD1a+ cells, infiltrated around the hair follicles. Without any additional treatment, her nodule rapidly decreased before we performed a second biopsy for analysis of the clonal gene rearrangement. Though PLF typically behaves as benign lymphohyperplasia, differentiation from cutaneous lymphoma is necessary.
\end{abstract}

\section{Introduction}

Pseudolymphomatous folliculitis (PLF) was first described as a variant of pseudolymphoma. It is characterized by a dense lymphoid infiltrate accompanied by hyperplastic hair follicles [1]. Clinically, PLF is described as a solitary dome-shaped or flat-elevated nodule, which is located on the face, scalp and trunk and is sometimes difficult to differentiate from primary malignant cutaneous lymphomas that may present as solitary nodules. A diagnosis of PLF is made based on hypertrophic hair follicles, perifollicular S100+ and CD1a+ dendritic cells, and negative clonal gene rearrangement study findings [2]. We present a case of PLF on the nose that resembled cutaneous lymphoma clinically, but histologically showed a benign proliferation of mixed polyclonal $\mathrm{T}$ and $\mathrm{B}$ cells surrounding and infiltrating a pilosebaceous unit. 


\section{Case Report}

A 57-year-old Japanese woman visited our outpatient clinic with a two-week history of a developing, asymptomatic nodule on her nose. On her initial visit, physical examination revealed a red, dome-shaped nodule, $12 \times 10 \mathrm{~mm}$ in size on the center of her nose (fig. 1). A biopsy specimen showed a dense lymphocytic infiltrate containing numerous histiocytes that surrounded and infiltrated hypertrophic hair follicles ( $\underline{\text { fig. } 2}$ a). The infiltrate is separated from the epidermis by a grenz zone (fig. 2a). There was no reactive pattern in follicular centers. (fig. 2a). Infiltrated cells were medium-sized with a high nuclear/cytoplasmic ratio and prominent nucleoli (fig. $2 \mathrm{~b}$ ).

Immunohistochemical staining revealed that the infiltrate consisted of a mixed population of $B$ $(\mathrm{CD} 79 \mathrm{a}+)$ and $\mathrm{T}(\mathrm{CD} 3+, \mathrm{CD} 4+, \mathrm{CD} 5+$ and CD8+) lymphocytes. CD1a-positive cells were densely infiltrated around the hair follicles (fig. 2c). Based on the above data, we diagnosed this patient as having PLF. Two weeks after we performed skin biopsy, the nodule was spontaneously decreased. Six months after the remission of the nodule, there was no sign of local recurrence.

\section{Discussion}

PLF is a rare manifestation of cutaneous pseudolymphoma and cutaneous lymphoid hyperplasia. As atypical lymphocytes can be observed in PLF, it must be differentiated from primary malignant cutaneous lymphomas, including small/medium-sized pleomorphic T cell lymphoma and follicle center B-cell lymphoma, and pilotropic mycosis fungoides [3-6]. However, in contrast to lymphomas, lymphocytes in PLF show no bias in their $\kappa-/ \lambda$-chain-positive $B$ cell ratio or $C D 4+/ C D 8+T$ cell ratio. Moreover, the distribution of CD1a+ dendritic cells around hair follicles is not a diagnostic feature of the cutaneous lymphomas [2].

PLF should also be differentiated from other cutaneous lymphoid hyperplasias $(\mathrm{CLH}) /$ pseudolymphomas $[2,6]$. In comparison with the various forms of CLH, there exist some similarities between PLF and pseudo-T-cell lymphoma. Indeed, pseudo-Tcell lymphoma may have a nodular appearance and be composed of a dense $\mathrm{T}$ cell infiltrate that may comprise numerous histiocytes and B cells [7].

The lesions of PLF demonstrate benign behavior, though atypical lymphocytes can be seen in PLF $[3,7,8]$. In our case, a solitary nodule on the nose rapidly developed during two weeks, underscoring the necessity of differentiation from variants of cutaneous lymphoma. Indeed, in our case, the first biopsy specimen revealed dense atypical lymphocytes with a high nuclear/cytoplasmic ratio and prominent nucleoli infiltrate containing numerous histiocytes that surrounded and infiltrated hypertrophic hair follicles without a reactive pattern to follicular centers. However, without any additional treatment, her nodule rapidly decreased before we performed a second biopsy for the analysis of clonal gene rearrangement, and finally we diagnosed this patient as having PLF. In this report, we present a case of PLF rapidly arising on the nose, which spontaneously regressed during the two weeks after the skin biopsy. PLF typically behaves as benign lymphohyperplasia, but for such tumors it may be difficult to determine the biological behavior or prognosis [2]. Dermatologists should differentiate PLF from primary malignant cutaneous lymphomas. 


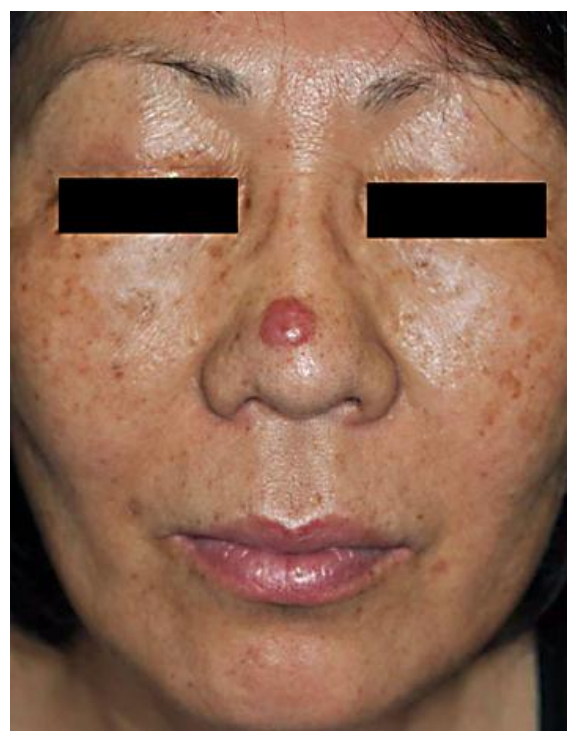

Fig. 1. A red, dome-shaped nodule, $12 \times 10 \mathrm{~mm}$ in size on the center of the nose.
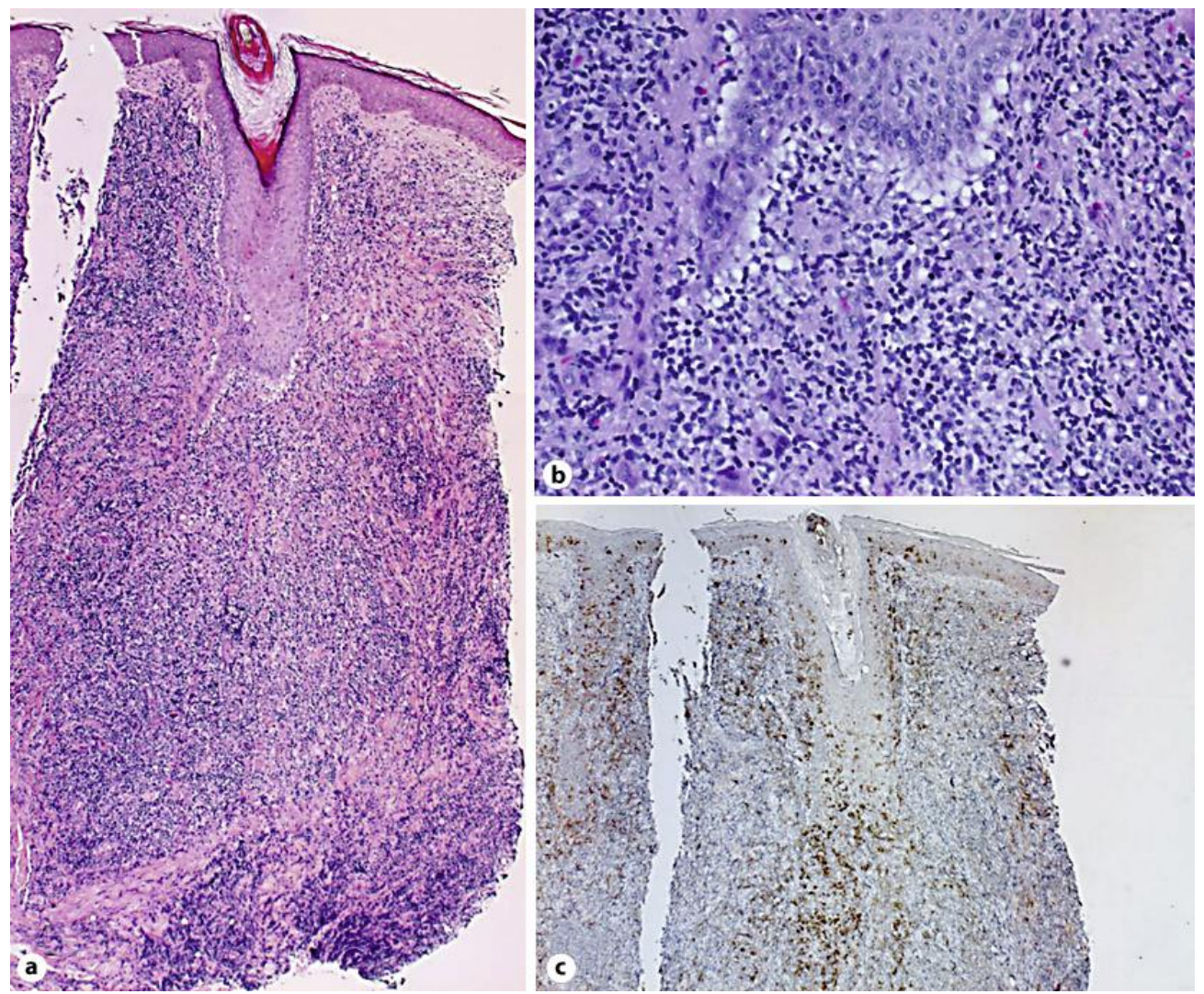

Fig. 2. A dense lymphocytic infiltrate containing numerous histiocytes that surrounded and infiltrated hypertrophic hair follicles. The infiltrate is separated from the epidermis by a grenz zone. There was no reactive pattern to the follicular centers. (a). Infiltrated cells were medium-sized with a high nuclear/cytoplasmic ratio and prominent nucleoli (b). CD1a-positive cells were densely infiltrated around the hair follicle (c). Original magnification $\times 50(a, c), \times 200(b)$. 


\section{References}

1 McNutt NS: Cutaneous lymphohistiocytic infiltrates simulating malignant lymphoma; in Murphy GF, Mihm MC (eds): Lymphoproliferative Disorders of the Skin. Boston, Butterworths, 1986, pp 256-285.

-2 Kwon EJ, Kristjansson AK, Meyerson HJ, Fedele GM, Tung RC, Sellheyer K, Tuthill RJ, Honda KS, Gilliam AC, McNiff JM: A case of recurrent pseudolymphomatous folliculitis: a mimicking of cutaneous lymphoma. J Am Acad Dermatol 2009;60:994-1000.

-3 Arai E, Okubo H, Tsuchida T, Kitamura K, Katayama I: Pseudolymphomatous folliculitis: a clinicopathologic study of 15 cases of cutaneous pseudolymphoma with follicular invasion. Am J Surg Pathol 1999;23:1313-1319.

4 Swerdlow SH, Campo E, Harris NL, Jaffe ES, Pileri SA, Stein H, Thiele J, Vardiman JW: WHO Classification of Tumours of Haematopoietic and Lymphoid Tissues. 4th ed. Lyon, France, IARC Press, 2008. WHO Classification of Tumours, vol 2, pp 145-147.

-5 Fujimura T, Aiba S, Yoshino Y, Kuroki S, Kimura Y, Kikuchi K, Kunii T, Matsunaga J, Matsushima K, Tagami H: CCR4 expression by atypical T cells in systemic pilotropic lymphoma: its behavior under treatment with interferon gamma, topical PUVA and systemic retinoid. Dermatology 2004;208:221-226.

-6 Van Doorn R, Scheffer E, Willemze R: Follicular mycosis fungoides, a distinct disease entity with or without associated follicular mucinosis: a clinicopathologic and follow-up study of 51 patients. Arch Dermatol 2002;138:191-198.

7 Dargent JL, Debois J, Sass U, Theunis A, Andre J, Simonart T: Unusual T cell pseudolymphoma with features of so-called pseudolymphomatous folliculitis. Dermatology 2002;204:159-161.

8 Lee HW, Ahn SJ, Choi JH, Moon KC, Koh JK: A case of pseudolymphomatous folliculitis. J Eur Acad Dermatol Venereol 2006;20:230-232. 